Abstract-The harbor seal (Phoca vitulina) is a large-bodied and abundant predator in the Salish Sea ecosystem, and its population has recovered since the 1970 s after passage of the Marine Mammal Protection Act and the cessation of bounties. Little is known about how this large predator population may affect the recovery of fish stocks in the Salish Sea, where candidate marine protected areas are being proposed. We used a bioenergetics model to calculate baseline consumption rates in the San Juan Islands, Washington. Salmonids (Oncorhynchus spp.) and herring (Clupeidae) were the 2 most energetically important prey groups for biomass consumed by harbor seals. Estimated consumption of salmonids was $783( \pm 380$ standard deviation [SD]) metric tons (t) in the breeding season and $675( \pm 388$ $\mathrm{SD} t$ in the nonbreeding season. Estimated consumption of herring was $646( \pm 303 \mathrm{SD}) \mathrm{t}$ in the breeding season and $2151( \pm 706 \mathrm{SD}) \mathrm{t}$ in the nonbreeding season. Rockfish, a depressed fish stock currently in need of population recovery, composed one of the minor prey groups consumed by harbor seals $(84[ \pm 26 \mathrm{SD}] \mathrm{t}$ in the nonbreeding season). The variables of seal body mass and proportion of prey in seal diet explained $>80 \%$ of the total variation in model outputs. Prey groups, such as rockfish, that are targeted for recovery may still be affected by even low levels of predation. This study highlights the importance of salmonids and herring for the seal population and provides a framework for refining consumption estimates and their confidence intervals with future data.

Manuscript submitted: 4 November 2011. Manuscript accepted 31 October 2012. Fish. Bull. 111:27-41 (2013). doi:10.7755/FB.111.1.3

The views and opinions expressed or implied in this article are those of the author (or authors) and do not necessarily reflect the position of the National Marine Fisheries Service, NOAA.

\title{
Fish consumption by harbor seals (Phoca vitulina) in the San Juan Islands, Washington
}

\author{
Sarah M. S. Howard (contact author) ${ }^{1}$ \\ Monique M. Lance ${ }^{2}$ \\ Steven J. Jeffries ${ }^{2}$ \\ Alejandro Acevedo-Gutiérrez ${ }^{1}$ \\ Email address for contact author: sarah_howard@nps.gov \\ 1 Biology Department \\ Western Washington University \\ 516 High Street \\ Bellingham, Washington 98225 \\ Present address: National Park Service \\ 10 Organ Pipe Drive \\ Ajo, Arizona 85321 \\ 2 Washington Department of Fish \& Wildlife \\ 7801 Phillips Road SW \\ Lakewood, Washington 98498
}

Overfishing and habitat change have affected fish populations heavily in the inland waters of the Pacific Northwest. Many formerly abundant fish species are now species of conservation concern, including groundfish stocks, such as rockfish species (Sebastes spp.) and Pacific Hake (Merluccius productus), forage fish stocks such as Pacific Herring (Clupea pallasii), and several salmonid species (Oncorhynchus spp.) (Musick et al., 2000; Mills and Rawson, 2004). Most recently, 3 rockfish species $(S$. ruberrimus, S. pinniger, S. paucispinis) were listed under the Endangered Species Act as threatened or endangered in Puget Sound, Washington State (Federal Register, 2010).

The decline of all these populations, which perform a critical function in regional food webs (Simenstad et al., 1979; Schindler et al., 2003) and have commercial and recreational value, has created a need for recovery strategies at the ecosystem level. Fish recovery efforts currently rely on traditional fisheries management approaches, such as reduction of fishing pressure and creation of no-take refuges or marine reserves, and on habitat restoration (Allison et al., 1998; Roni et al., 2002). Marine reserves in particular are more likely to be successful for species, such as rockfish, that have small home ranges and high site fidelity (Love et al., 2002), and reserves are important management tools for recovery of rockfish in the Pacific (Murray et al., 1999). More reserves have been proposed recently for the San Juan Islands, ${ }^{1}$ an island group that is part of the Salish Sea marine ecosystem that spans U.S. and Canadian waters (Fig. 1). For pelagic species, such as salmonids and forage fishes, recovery efforts call for habitat protection and mitigation of water-pollution issues, among other factors, as management tools (Fluharty, 2000; Schindler et al., 2003).

The restoration of predators in marine ecosystems can reestablish trophic relations and restructure habi-

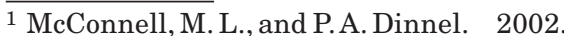
Rocky reef bottomfish recovery in Skagit County. Phase II final report:assessment of eight potential marine reserve sites $\&$ final site recommendations. Skagit County Marine Resources Committee, Mount Vernon, WA, 43 p. [Available from http://www.nwstraits.org/Archives/ Library.aspx.]
} 
tat with usually positive results (Shears and Babcock, 2002; Shears et al., 2006); however, predators also can cause declines in the size distributions and abundance of prey species inside marine reserves (Sala and Zabala, 1996; Fanshawe et al., 2003). Large-bodied and abundant predators can contribute significantly to fish mortality, especially when prey species are already low in abundance, and may theoretically influence prey population recovery (Mohn and Bowen, 1996; Bundy, 2001; DeMaster et al., 2001; Fu et al., 2001; Trzcinski et al., 2006). Therefore, there is a need to understand the prey requirements of predators that consume fish species of conservation concern to evaluate if such requirements conflict with regional management goals.

In the Salish Sea, the harbor seal (Phoca vitulina) is an abundant, generalist marine predator whose population has steadily increased since gaining protected status in the 1970s. The harbor seal population in Washington State experienced logistic growth from the 1970s to the 1990s, increased 7- to 10 -fold in size in different regions, and now appears to be at carrying capacity (Jeffries et al., 2003). Estimates of the regional population in the San Juan Islands and eastern bays in the early 1970s were approximately 1000 animals; currently, there are approximately $8000 .^{2}$ The age structure of the harbor seal population in British Columbia was documented in Bigg (1969), on the basis of seals collected and aged in the $1960 \mathrm{~s}$. After exponential population increases, this population was heavily weighted toward juvenile age classes by the 1980s (Olesiuk, 1993). Given the population increase in all regions of the Salish Sea, the current age structure of the harbor seal population in the San Juan Islands is unknown.

As with other harbor seal populations in the eastern Pacific, harbor seals in the San Juan Islands take advantage of the large influx of adult salmonids in late summer and fall and increase the diversity of their diet at other times of the year when salmonids are less available (Hauser et al., 2008; Lance et al., 2012). Salmonids, Pacific Herring, Pacific Sand Lance (Ammodytes hexapterus), Northern Anchovy (Engraulis mordax), Walleye Pollock (Theragra chalcogramma), and estuarine species, such as Shiner Perch (Cymatogaster aggregata), also form significant proportions of their diet in the San Juan Islands and nearby estuarine ecosystems (Lance et al., 2012).

\footnotetext{
${ }^{2}$ Washington Department of Fish \& Wildlife. Unpubl. data. Washington Department of Fish \& Wildlife, 7801 Phillips Road SW, Lakewood, WA 98498.
}

To calculate population-level consumption of fish species of conservation concern and other common harbor seal prey in the San Juan Islands, a bioenergetics model was used to determine energetic requirements. The model incorporated seasonal changes in seal diet and life history parameters during breeding and nonbreeding seasons. We also used simulated data and sensitivity analyses to address uncertainty in the overall model and in 2 specific components that may have a strong influence on predicted consumption of prey: 1) uncertainty in age structure of the harbor seal population and 2) seasonal changes in energy intake (e.g., fasting during breeding season).

\section{Methods}

\section{Area and timeframe of study}

The region of the San Juan Islands and eastern bays is an area where many fish species of conservation concern occur and also an area where the majority of the harbor seal population resides in the inland waters 
of Washington State. The San Juan Islands $\left(48^{\circ} 35^{\prime} \mathrm{N}\right.$, $122^{\circ} 55^{\prime} \mathrm{W}$ ) are characterized by tidally influenced rocky reefs and isolated rocks surrounded by deep water where harbor seals often congregate at haul-outs (locations where seals come ashore). The adjacent eastern bays, in contrast, consist of large, soft-bottomed, shallow bays $\left(48^{\circ} 33^{\prime} \mathrm{N}, 122^{\circ} 30^{\prime} \mathrm{W}\right)$ (Fig. 1 ).

The consumption model was constructed for a single annual cycle for the harbor seal population during 2007-08. The model included 2 seasons: breeding (15 June-15 September) and nonbreeding (16 September-14 June) determined on the basis of seal pupping phenology in the San Juan Islands (Huber et al., 2001; Patterson and Acevedo-Gutiérrez, 2008). The 2 seasons were delineated to reflect known behavioral shifts (more time spent ashore to nurse pups, shallow-water breeding displays by males) related to pupping and breeding activities and subsequent changes in energetic expenditures (Coltman et al., 1998; Bowen et al., 1999).

The model was programmed in $\mathrm{R}$ software, vers. 2.7.1 ( $R$ Development Core Team, 2008) and used regional activity, abundance, and diet data, as well as physiological data from the literature. Model parameters were grouped into 3 categories: bioenergetics, population, and diet (Lavigne et al., 1982; Winship et al., 2002) (Table 1).

\section{Model structure}

Bioenergetics Energetic requirements were calculated with a bioenergetics approach that described the energy budget of an individual seal, which is a function of body size, activity budgets, growth, and reproductive costs. Sex- and age-specific gross energy requirements were calculated with Equation 5 in Boyd (2002):

$$
\frac{E G_{i}=\left[\sum_{f=1}^{f=n_{\text {activities }}}\left(\gamma_{f} q_{f, i}\right) 86400\right]+g_{i}}{\sum^{d_{i}}},
$$

where $E G_{i}=$ energy requirements in a particular stage $i$ of the annual cycle;

$\gamma_{f}=$ the power (watts) generated under activity $f$ within stage $i$ of the annual cycle;

$q_{f, i}=$ proportion of time spent in activity $f$

$g_{i}=$ the cost of growth in stage $i$ of the annual cycle; and

$d_{i}=$ the digestive efficiencies of food being eaten.

The model had 6 sex-and-age classes: 1) adult females ( $>6$ years), 2 ) adult males (>8 years), 3 ) subadult females (1-6 years), 4) subadult males (1-8 years), 5) female pups ( $<1$ year), and 6 ) male pups ( $<1$ year). The subadult to adult division was made at the age(s) harbor seals reach their predicted maximum weight (approximately $66 \mathrm{~kg}$ and $89 \mathrm{~kg}$ for females and males, respectively) on the basis of the growth curve in Ole- siuk (1993). Daily growth increments for each sex-andage class were calculated from the same growth curve. Activity budgets were estimated from free-living harbor seals tagged with data recorders that recorded 3 behavioral periods: haul-out, diving, and shallow-water activity (Table 1).

Population abundance and age structure Aerial population surveys of harbor seals have been conducted annually by the Washington Department of Fish \& Wildlife with fixed-wing aircraft to estimate the number of animals hauled-out during the lowest tide of the day since 1978 (Jeffries et al., 2003). Results from these surveys were used to estimate the abundance of harbor seals in the study area in 2007-08. The breeding season (July) correction factor of 1.53 (to account for seals not hauled-out at the time of the survey) was used to estimate the size of the breeding season population (Huber et al., 2001). Age-dependent mortality rates in Olesiuk (1993) were used to estimate the age structure (number of seals in each sex-and-age class) of the harbor seal population:

$$
N_{s(x+t)=N_{s(x)} e^{-r t}}
$$

where $N_{S(x)}=$ number of seals in sex class $S$ and age class $x$;

$-r=$ the age-dependent mortality rate; and

$t=$ time interval between age classes.

The breeding season population vector was adjusted by iteration to sum to the total population estimate from aerial surveys. Seal abundance in the nonbreeding season was calculated by estimating the numbers still alive in each sex-and-age class, by using the same age-dependent mortality rates calculated per day (instead of annually) and by multiplying the number of days in the breeding cycle.

Population energetic requirements were calculated by multiplying individual requirements by the population abundance vectors to estimate energetic requirements for each sex-and-age class. Reproductive costs were then calculated for the entire population on the basis of values from the literature for gestation and lactation costs and fertility rates (Bigg, 1969; Olesiuk, 1993).

Digestive efficiency Data from the literature were used to translate net energy requirements of the harbor seal population into gross energy requirements and prey consumption by first taking into account assimilation efficiency and the heat increment of feeding (the increase in metabolism or heat produced during digestion) for harbor seals. We used the minimum and maximum values reported in the literature to account for differences in digestive efficiencies related to protein and fat content of prey (Markussen et al., 1994; Trumble et al., 2003). 


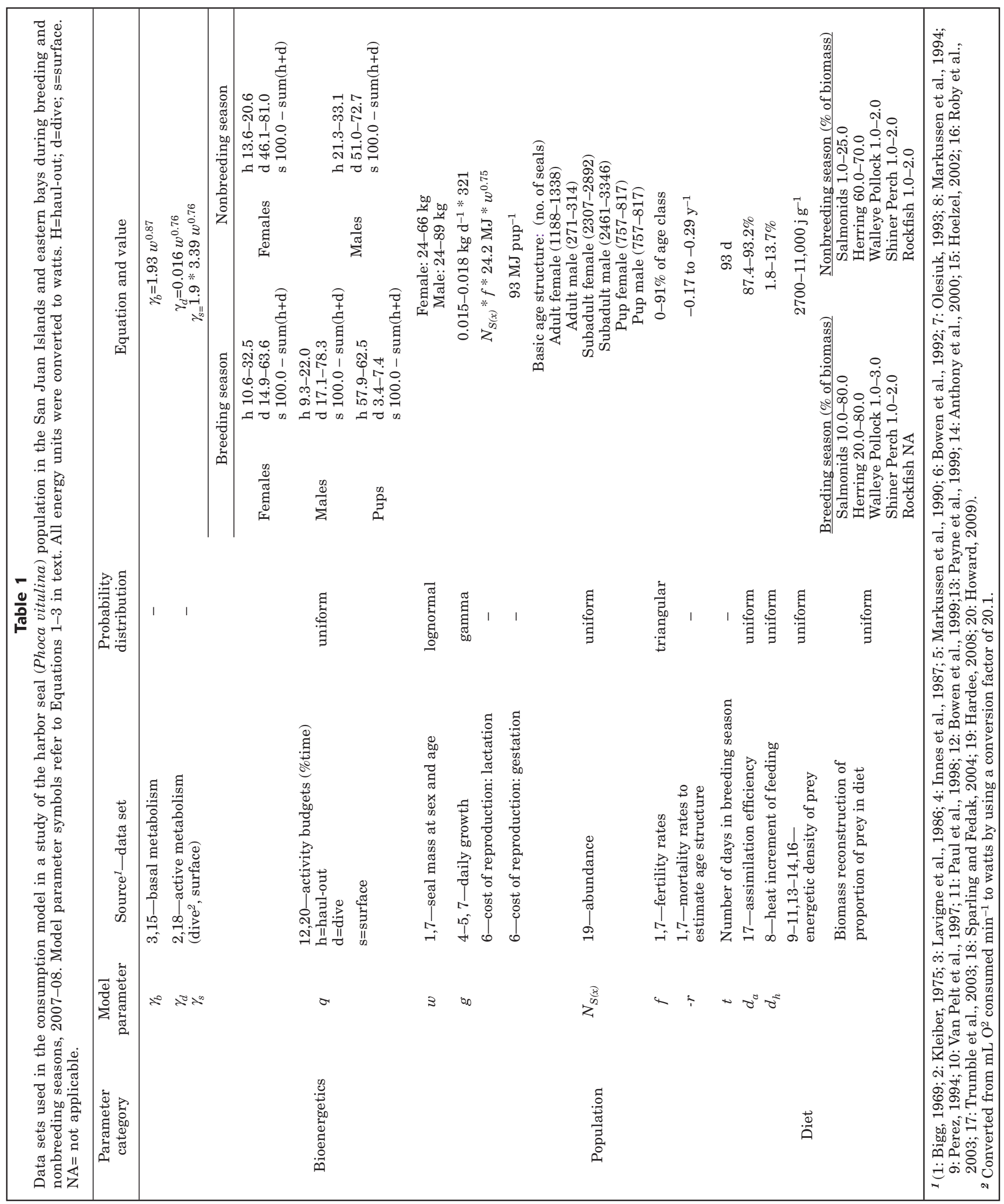




\section{Diet}

Collection of scat samples Scat samples were collected at 23 sites that represented regional variation in habitat in the San Juan Islands from 2005 to 2008 as part of a larger harbor seal diet study conducted in the northern Puget Sound (Fig. 1) (Lance et al., 2012). Samples collected during seal breeding and nonbreeding seasons in 2007-08 were used in our study. Detailed scat sample processing, collection information, and analysis of frequency occurrence of prey items in harbor seal diet are summarized in Lance et al. (2012). Briefly, samples for the diet study were collected from harbor seal haul-out locations during daytime low tides, placed in plastic bags, and then frozen until they were processed. Scat samples were processed following Lance et al. ${ }^{3}$ and Orr et al. (2003). Otoliths were measured and graded according to the methods of Tollit et al. (2007). On otoliths that were graded as good (no or minimal erosion) and fair (small amount of erosion), the width and length were measured with an ocular micrometer. For our study, scat samples were pooled by seal breeding and nonbreeding seasons for further analyses.

Reconstruction of wet biomass To choose appropriate input values for diet in the model, a wet biomass reconstruction technique (Laake et al., 2002) was used to estimate the proportion by wet weight of prey items in harbor seal diet. This technique focuses on energetic content of seal diet, rather than on frequency of items in diet, by accounting for the number and size of prey consumed in a diet sample. The proportion of wet biomass of a prey item $\left(\pi_{i}\right)$ in harbor seal diet was calculated by (Laake et al., 2002):

$$
\pi_{i}=\frac{n_{i} w_{i}}{\sum_{i=1}^{w} n_{i} w_{i}}
$$

where $n_{i}=$ the corrected number of items of prey item $i$; and

$w_{i}=$ the average weight (in grams) of all prey items $i$.

The corrected number of "items" ( $n_{i}$, number of individuals in the sample) was calculated by applying a species-specific (or closest proxy) correction factor to account for otolith loss during digestion. We used otoliths to enumerate all species except Shiner Perch, for which we used the number of pharyngeal plates to derive a more reliable passage rate. We lacked otolithloss correction factors for herring (Clupeidae) and Walleye Pollock; therefore, we considered the correction factors for Pacific Sardine (Sardinops sagax) and Pacific Hake in Phillips and Harvey (2009), respectively, to

${ }^{3}$ Lance, M. M., Orr A. J., Riemer S. D., Weise M. J., and Laake J. L. 2001. Pinniped food habits and prey identification techniques protocol. AFSC Processed Report 2001-04, 41 p. Alaska Fisheries Science Center, Seattle, WA. [Available from http://access.afsc.noaa.gov/pubs/search.cfm.] be reasonable proxies because these species are similar in size and structure (M. M. Lance, personal commun.). We used a Pink Salmon (Oncorhynchus gorbuscha) otolith-loss correction factor for all salmonids, a Shortbelly Rockfish (Sebastes jordani) correction factor for all rockfish species, and species-specific correction factors for Shiner Perch and Pacific Staghorn Sculpin (Leptocottus armatus) (Harvey, 1989; Phillips and Harvey, 2009).

Length correction factors were applied to measurements from otoliths scored as being in good or fair condition to account for otolith erosion during digestion. Corrected otolith lengths then were used to calculate the fish size with species-specific length-weight regressions (Harvey et al., 2000). When we lacked speciesspecific correction factors or length-weight regressions, we used estimated body sizes of prey items.

Otoliths of juvenile and adult salmonids were distinguished on the basis of otolith and bone sizes. Otoliths that were graded in good enough condition to measure and reconstruct salmonid size were uncommon in scat samples; therefore, for salmonid adults that were not identified to species, we used an approximate average size (1589 g) for Pink Salmon, the species most commonly consumed by harbor seals (Lance et al., 2012). An average estimated size of $35 \mathrm{~g}$ was used for all salmonid juveniles. We also lacked otolith-length correction factors for herring and Walleye Pollock; therefore, we used Pacific Sardine and Pacific Hake as proxies. The remaining length correction factors that we used were a Shortbelly Rockfish correction factor for all rockfish species, and species-specific correction factors for Shiner Perch and Pacific Staghorn Sculpin.

It should be noted that reconstruction was not possible for all species in the diet samples because of the diversity of harbor seal diet and lack of appropriate correction factors as noted previously and in Table 2 . Given the complexity of harbor seal diet and lack of reconstruction techniques for several species, we reconstructed the proportion in the sample only for prey species of conservation concern or for prey species whose frequency of occurrence was $\geq 5.0$ in the broader study of harbor seal diet (Lance et al., 2012). Our goal was to set a reasonable range of values for model input in addition to describing diet composition; therefore, we make here a distinction between diet sample results and the parameter values used in the model to calculate consumption. When there was great uncertainty in percent contribution by wet weight to harbor seal diet because of the use of proxy correction factors or omission of some species from biomass reconstruction, confidence intervals were increased (see Model uncertainty and parameter estimation section).

\section{Consumption rates}

We calculated consumption (as biomass) for 5 key prey species or groups that are species of conservation concern or most common in harbor seal diet: her- 


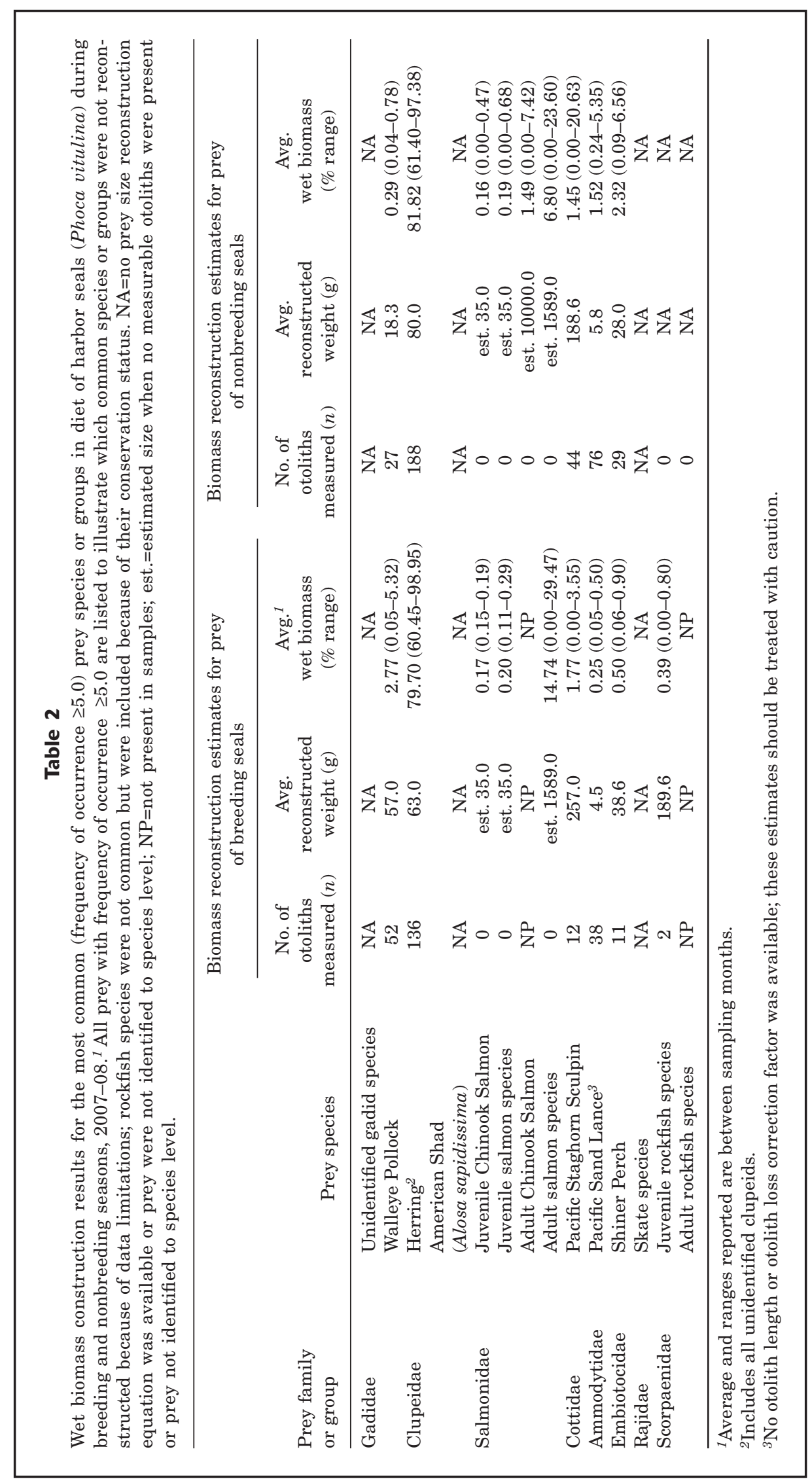


ring, salmonids, rockfish, Walleye Pollock, and Shiner Perch. Gross energy requirements were translated to consumption rates by applying the energetic density of prey to the proportion by wet weight of prey items in seal diet (Perez, 1994; Van Pelt et al., 1997; Paul et al., 1998; Payne et al., 1999; Anthony et al., 2000; Roby et al., 2003). After biomass reconstruction, all species of adult and juvenile salmonids were combined into a "salmonid" complex. A "herring" complex represented Clupea pallasii and unidentified clupeid species. There are 2 other clupeid species in the study area, but, because of their rareness, we assumed most species were C. pallasii (M.M. Lance, personal commun.). When prey were placed into broader taxonomic groups, we used the minimum and maximum values for energetic density reported for all prey sizes and ages in the literature to represent the prey group.

\section{Model uncertainty and parameter estimation}

Model variables described in Table 1 were randomly chosen during 1000 simulations from probability distributions to estimate uncertainty in all model outputs. Where estimation of distribution parameters was not straightforward (e.g., lognormal), a maximum likelihood technique with the MASS package in R was used; this technique estimates the joint likelihood for distribution parameter values, given the seal body mass values for each sex-and-age class (Venables and Ripley, 2002). We also made the following changes to diet results to adjust the uniform distribution parameters for percentage by wet weight of prey in diet. If we had set the minimum and maximum values for a uniform distribution for proportion in diet exactly as found in diet samples, it would have been uninformative (i.e., a range of 0-100 often occurred but would imply no prior knowledge of diet composition; Table 2). Therefore, zero values from diet samples were discarded and minimum values for herring and salmonids were set as calculated from the remaining diet samples. For Shiner Perch and Walleye Pollock, zero values also were discarded. The minimum possible value was assumed to be $1 \%$, and the maximum value was set near the average calculated from diet samples. Harbor seal diet is diverse; therefore at least $20-30 \%$ of harbor seal diet was assumed to be made up of other species, and the maximum value possible for any prey species was set at $70-80 \%$ (the maximum value for nonbreeding season was set slightly lower because of increased diversity of diet). All model outputs are reported as means ( \pm standard deviation).

Sensitivity analyses also were used to identify parameters with the most influence on model outputs by systematically allowing one parameter at a time to be chosen randomly while other variables were fixed at their mean value(s). In this manner, any variation in the model outputs should be the direct result of variation in the parameter of interest (Shelton et al., 1997; Stenson et al., 1997; Winship et al., 2002). The percent- age of variance explained by a single variable was calculated as the variance of model outputs when single random variables were used and divided by the total variance when all variables were randomly chosen.

To estimate the effect of age structure on total prey consumption, we used different ratios of adults to subadults in 3 alternate model scenarios. We increased the number of adults in the population by $25 \%, 50 \%$, and $100 \%$ and kept the total population size stable.

During the breeding season, adult harbor seals fast or reduce consumption (Bowen et al., 1992; Coltman et al., 1998); therefore, there may be a discrepancy between predicted energy requirements and timing of consumption during an annual cycle. Rather than use direct consumption, we addressed the effect of this discrepancy with a correction factor that accounted for energy obtained from burning body fat stores in the breeding season. We estimated the amount of energy consumed, stored as body fat, and later metabolized by adult seals with the same estimates of digestive efficiency and energy density of prey that were used in the overall consumption model.

\section{Results}

\section{Fish consumption}

There were 196 and 361 scat samples collected during the breeding and nonbreeding seasons, respectively. In these samples, 23 and 29 prey taxa were identified during the breeding and nonbreeding seasons. Ten prey taxa were selected for reconstruction in this study; they had a frequency of occurrence $\geq 5.0$ in the broader harbor seal diet study (Lance et al., 2012) or were species of conservation concern. Of these 10 taxa, 3 prey groups (unidentified gadid, skate species, and American Shad [Alosa sapidissima]) could not be used because we had insufficient methods (e.g., lack of correction factors) to reconstruct their presence in seal diet. Of the remaining prey, herring comprised the vast majority of reconstructed samples: $\geq 80 \%$ of wet weight in both breeding and nonbreeding seasons. Salmonids composed $15 \%$ and $9 \%$ in the breeding and nonbreeding seasons, respectively (Table 2). We were not able to identify rockfish otoliths to species in either season. In the breeding season, rockfish frequency of occurrence was $0.5 \%$ and therefore was assumed to contribute little in energetic terms to diet and was not further considered for calculation of consumption rates. Measurable otoliths were not found for rockfish species in the nonbreeding season; therefore, we were unable to determine species or size. During the nonbreeding season, rockfish frequency of occurrence was $1.4 \%$ (Lance et al., 2012); we set a hypothetical range for proportion of wet weight of rockfish in diet at 1.0-2.0\%. Walleye Pollock and Shiner Perch constituted a relatively minor portion (averages $0.5-2.8 \%$ ) of reconstructed diet (Table 2). 


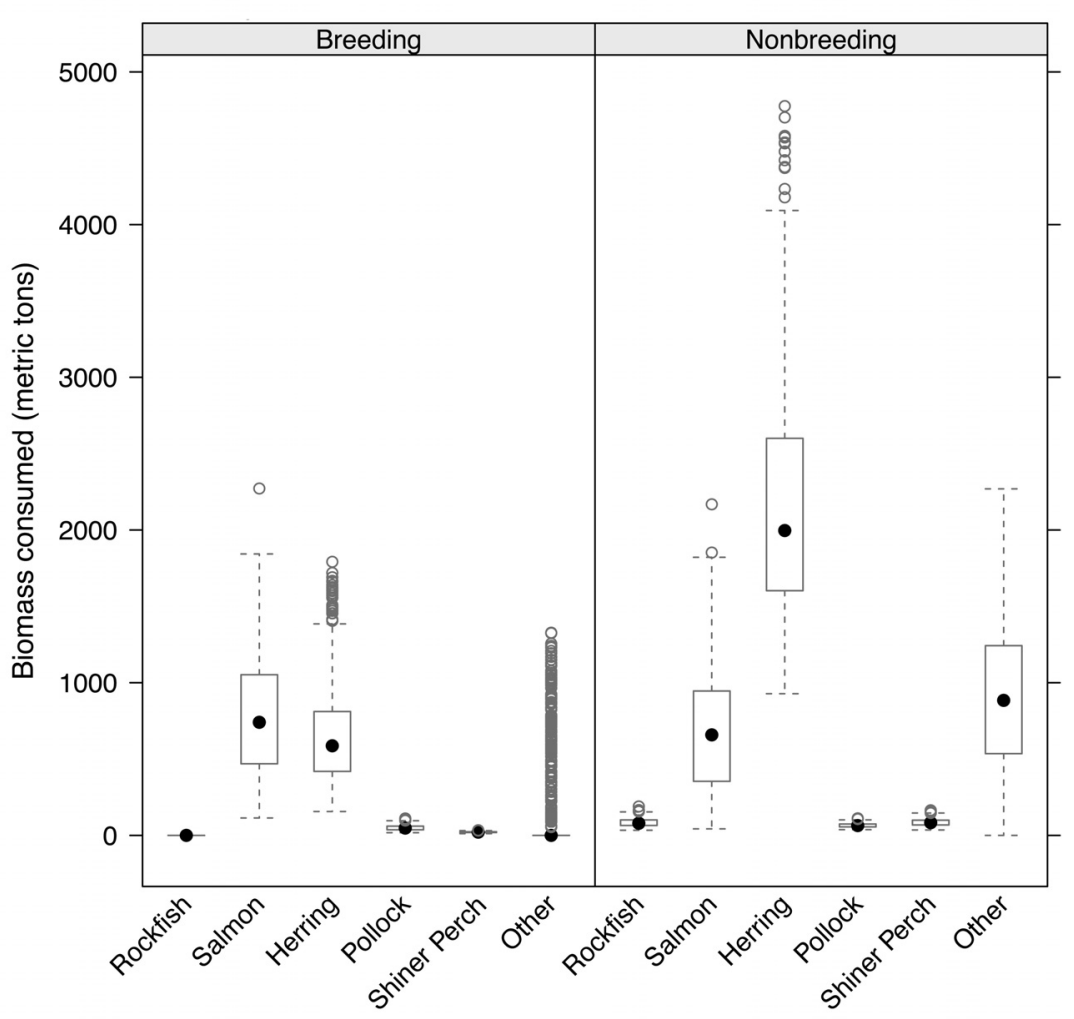

Figure 2

Estimates of consumption of prey species, relative to season (breeding or nonbreeding), for the harbor seal (Phoca vitulina) population in the San Juan Islands and eastern bays during 2007-08. "Other" category represents remaining prey in seal diet. Solid circles indicate medians, boxes enclose the interquartiles, vertical dashed lines represent $1.5 \times$ the interquartile range, and open circles indicate outliers.

During the seal breeding season, the average consumption for prey species calculated over 1000 simulations was $783( \pm 380)$ metric tons $(\mathrm{t})$ of salmonids, $646( \pm 303) \mathrm{t}$ of herring, $50( \pm 17) \mathrm{t}$ of Walleye Pollock, and $22( \pm 4)$ t of Shiner Perch (Fig. 2). Subadult seals of both sexes consumed the greatest proportion of the total biomass (approximately 30-40\% each), followed by adult females (27\%). Adult males consumed a relatively small proportion of total biomass compared with adult females and subadults, and their consumption was only slightly higher than the biomass consumed by pups of both sexes (each $<10 \%$ ).

During the nonbreeding season, consumption of herring and salmonids had the widest range of values; rockfish, Shiner Perch, and Walleye Pollock were less variable. The average consumption for prey species calculated over 1000 simulations was $84( \pm 26)$ $\mathrm{t}$ of rockfish, $675( \pm 388) \mathrm{t}$ of salmonids, $2151( \pm 706)$ $\mathrm{t}$ of herring, $66( \pm 13) \mathrm{t}$ of Walleye Pollock, and $86( \pm 22)$ $\mathrm{t}$ of Shiner Perch (Fig. 2).

The per capita fish consumption rate predicted by the model was $2.1 \mathrm{~kg}$ day $^{-1}$ seal $^{-1}$ (annual average $2.9,2.8$, $2.0,2.2$, and $1.0 \mathrm{~kg}$ for adult females, adult males, subadult females, subadult males, and pups, respectively). As was evident during the breeding season, subadults (which included pups from the previous breeding season) of both sexes consumed the greatest proportion of the total biomass (approximately 30-45\% each), followed by adult females (19\%). Adult female consumption dropped slightly in the nonbreeding season. Adult males consumed the smallest proportion in the population (5\%).

\section{Sensitivity analyses and assessment of model uncertainty}

Variation in seal body mass had the largest effect on energy use of the population and accounted for $>80 \%$ of model variance in both seasons. Taken together, all bioenergetics variables (mass, growth rates, and activity) accounted for the majority of the variance in the simulation model. Fertility rates accounted for the next-greatest variance (7.3\%) after body mass during the breeding season while population size contributed least $(1.3 \%)$ to overall model variabil-

ity (Fig. 3).

Consumption estimates of salmonids and herring were most sensitive to estimates of proportion of prey in the diet and energy density of prey. Variation in consumption estimates was low when the heat increment of feeding and assimilation efficiency parameters were varied within their estimated ranges. The variance in the nonbreeding season seen in the overall simulation model for both salmonids and herring was not well explained by any single prey variable (Fig. 4).

We estimated that adult seals used approximately $1,100,000 \mathrm{MJ}$ of fat stores during the breeding season. Assuming an average prey energy density of $4000 \mathrm{~J}$ $\mathrm{g}^{-1}$, this use of energy was equivalent to consumption of $300 \mathrm{t}$ or approximately $6 \%$ and $21 \%$ of annual and breeding-season energy use, respectively. Increasing the number of adult seals in the population led to a positive increase in population energy use, although at a relatively slow rate of increase: even when we doubled the number of adults in the population, energy use increased only by $7 \%$ (Fig. 5). 


\section{Discussion}

The prey consumption model was quite sensitive to body mass: when body mass was varied $\pm 10 \%$ around the average, there was a corresponding $\pm 10 \%$ change in the energy use outcome. Body mass controls many physiological functions in organisms, and because massbased predictive relationships were used for metabolic rate, the sensitivity of the model to body mass was not entirely unexpected. By simply accounting for body size and number of harbor seals, the model captured the bulk of energy use in the population. In fact, omission of reproduction costs (lactation and gestation costs) did not affect estimates of nonbreeding season energy use and lowered breeding season estimates by approximately $10 \%$.

Predicted per capita fish consumption of $2.1 \mathrm{~kg} \mathrm{day}^{-1} \mathrm{seal}^{-1}$ fell within the range estimated for the harbor seal populations in British Columbia, Canada, and Norway: $1.9 \mathrm{~kg}$ and $4 \mathrm{~kg}$, respectively (Härkönen and Heide-Jørgensen, 1991; Olesiuk, 1993; Bjørge et al., 2002). Despite their large body size, adult males were the least numerous sex-and-age class in the population-information that explained their low proportion of total population consumption when the population was considered as a unit. Consumption was for the most part proportional to the biomass of the total seal population; therefore, any change in total population size would correspond to a roughly equal percent change in estimated consumption. With this prediction, all other model variables were assumed to be similar among years, and this assumption seems reasonable given that the total population size has stabilized during the last decade ${ }^{2}$ (Jeffries et al., 2003). Nevertheless, at dramatically different population sizes, there may be different behavioral or population changes that would need to be taken into account (e.g., individual prey preferences, intraspecific competition, fertility rates, and mortality rates) to predict population consumption.

In contrast to the other population variables, only point estimates were used for mortality rates. The age structure of the harbor seal population used in the basic consumption model was heavily dominated by sub- adults, and the population structure was based on data from a time period when the harbor seal population was depressed. However, changing the age structure in our alternative model (see Appendix) caused relatively minor changes in the energy budget, especially compared with the sensitivity of the model to body mass. If the increase in population size since the 1970s has led to decreased juvenile survival rates, as is predicted to be the case for marine mammals (Fowler, 1981; Hiby and Harwood, 1985), and adult seals are now more dominant in the population, overall consumption rates still should be similar to those that we predicted, at least at the adult to subadult ratios that were tested in alternate model versions.

For species, such as harbor seals, that use fat stores during fasting periods, inferring consumption directly from energetic requirements may be somewhat misleading. Harbor seals fast or reduce feeding rates for 2-6 weeks and can lose up to $33 \%$ of body mass during the breeding season (Bowen et al., 1992; Coltman et 


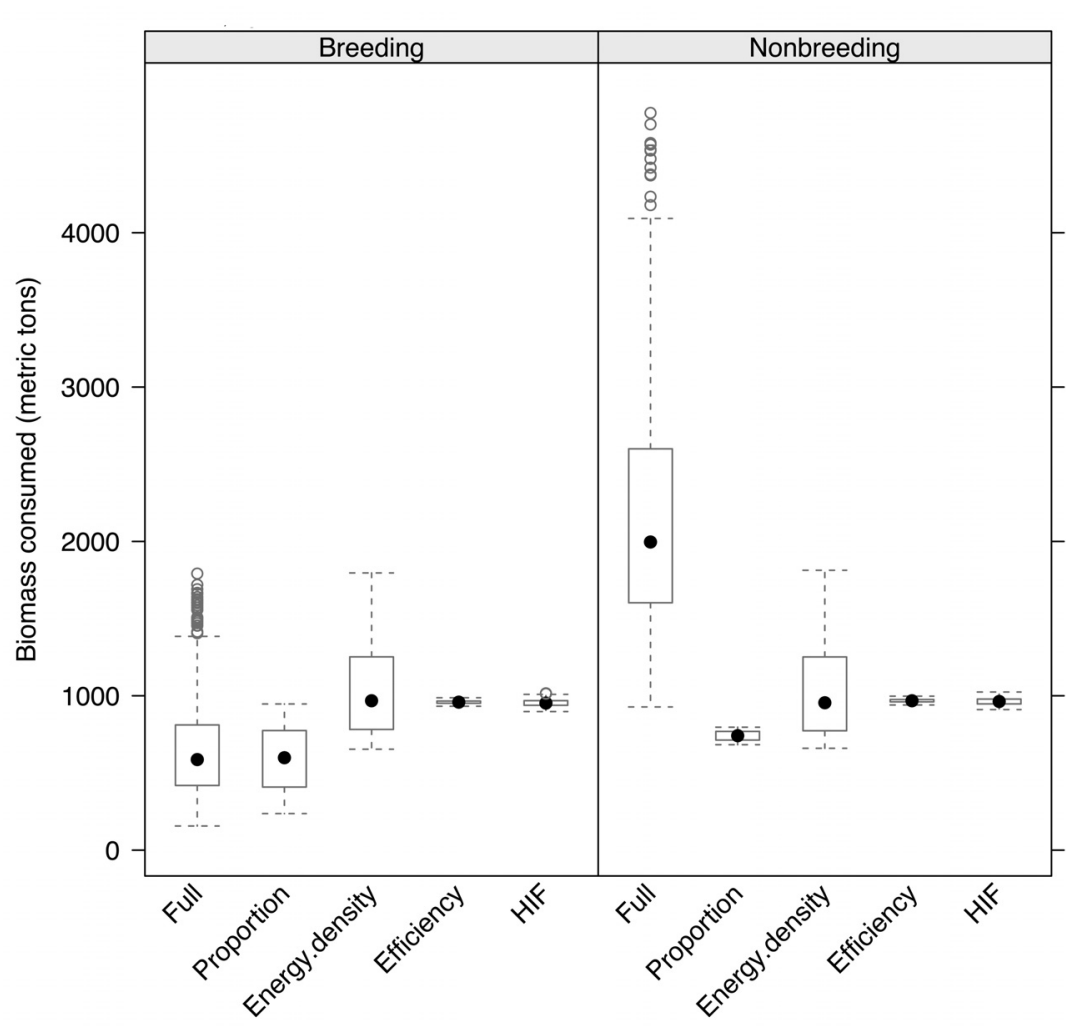

Figure 4

Effect of prey variables on herring consumption of harbor seals (Phoca vitulina) relative to season (breeding or nonbreeding), in the San Juan Islands and eastern bays during 2007-08. Distribution of model outputs after running 1000 simulations with all ("Full") or single variables selected randomly. Proportion=percent of total biomass in seal diet composed of herring (\%). Energy density=energy contained in prey items $\left(\mathrm{J} \mathrm{g}^{-1}\right)$. Efficiency=percent of gross energy available in prey item that is metabolizable (\%). HIF=heat increment of feeding (\%). Solid circles indicate medians, boxes enclose the interquartiles, vertical dashed lines represent $1.5 \times$ the interquartile range, and open circles indicate outliers. All simulations allowed variance in seal energetic requirements.

al., 1998). Pinnipeds increase feeding rates either immediately after the breeding season or before the next breeding season to regain fat stores (Beck et al., 2003). In addition, there are seasonal changes in energy intake that occur in harbor seals and other pinnipeds (Schusterman and Gentry, 1971; Rosen and Renouf, 1998). We addressed this discrepancy in timing of predicted energetic requirements and feeding through assessment of how much prey may be consumed by adult seals in the winter and spring and later used as fat stores. We found the amount to be a minor proportion of annual consumption but a more significant portion of the breeding season estimates. Therefore, the effect of consumption in the breeding season may be reduced, and consumption during the winter may be higher than we predicted.

Bioenergetic variables (especially body mass) contributed most to sensitivity in calculations of energy requirements in this study. Other pinniped consumption models similarly have identified body mass and body-mass predicted energetic requirements as a significant source of model variation (Mecenero et al., 2006; Chassot et al., 2009). When the full consumption model was examined, the assumed proportion of each prey species in the diet had the largest effect on consumption outputs-a result that was also similar to other pinniped consumption models (Mohn and Bowen, 1996; Shelton et al., 1997; Mecenero et al., 2006; Overholtz and Link, 2007), suggesting that future effort should be focused on refining the contribution of different prey to harbor seal diet. Genetic and molecular techniques increasingly are used to identify diet composition (Casper et al., 2007; Deagle and Tollit, 2007). It is likely necessary to evaluate the diet of generalist marine predators with a combination of techniques, given that these techniques often yield different results and can answer different questions (Tollit et al., 2006). The model described here can be used to test assumptions about the relative importance of salmonids and herring compared with other species in harbor seal diet as other data become available.

Estimates indicate that rockfish species constituted a relatively minor proportion of total consumption by harbor seals. There are more than 26 species of rockfish that occur in the inland waters of Washington State, and many species are listed as endangered by the state. Under the federal Endangered Species Act, 2 species are listed as threatened and 1 species is listed as endangered. The 2 most dominant species, Copper (Sebastes caurinus) and Quillback (S. maliger) Rockfish, for which abundance data are well documented, have both undergone serious declines and are considered vulnerable to extinction (Mills and Rawson, 2004). For depressed species such as these, even small amounts of predation may be significant. If we assume an average size of $1 \mathrm{~kg}$ for a rockfish in harbor seal diet (ignoring age- or species-size differences), harbor seals hypothetically consumed 84,000 rockfish individuals in 2007-08 in the San Juan Islands and eastern bays. However, to illustrate the importance of age or species preference by harbor seals, if we assume that harbor seals eat only 
Puget Sound Rockfish (S. emphaeus; the smallest of the rockfish at $\sim 40 \mathrm{~g}$ ), they could have consumed more than 2 million individuals, a number that presumably can affect the rockfish population. It seems clear that prey that constitute even a minor proportion of harbor seal diet may be affected by predation, if such predation increases their natural mortality rates. Therefore, harbor seal interactions with prey species of management concern merit further attention, and modeling prey vulnerability to predation will require a multidisciplinary approach.

Consumption estimates calculated in this study illustrate the energetic importance of herring and salmonids to harbor seals in the San Juan Islands and the importance of considering predation effects on prey groups from multiple perspectives. In this study, we contrasted high consumption rates of prey species (salmonids and herring) with less commonly consumed prey groups, such as rockfish, to illustrate the capacity of models to test assumptions in situations with high uncertainty in input values, such as percentage by wet weight of rockfish in seal diet. We provided evidence that the apparently minor contribution of rockfish biomass to harbor seal diet may nevertheless indicate that large numbers of individuals are being consumed, but the number consumed is highly dependent on the species and age of prey. Harbor seals consumed large amounts of the more commonly consumed species, such as herring, even at the lower estimated limits of consumption rates calculated in this study. Many herring stocks have undergone critical declines, and there is concern that pinniped predation may have increased the natural mortality rate of herring in some areas (Musick et al., 2000), although it is acknowledged that there are likely many factors that contributed to the decline of herring (Stout et al., 2001). Spawner biomass of herring for the northern Puget Sound, an index of population abundance, remained low through the study period, ${ }^{4}$ yet herring has been identified as one of the top prey species of

\footnotetext{
${ }^{4}$ Stick, K. C., and A. Lundquist. 2009. 2008 Washington State herring stock status report. Stock Status Report FPA 09-05, 111 p. Washington Department of Fish \& Wildlife, Fish Program, Fish Management Division. [Available from http://wdfw.wa.gov/publications.]
}

harbor seals in a San Juan Islands diet study since 2005 (Lance et al., 2012).

Like herring populations, salmonid populations have undergone serious declines, and there is also concern that pinnipeds may affect salmonid recovery (NMFS, 1997; Wright et al., 2007). Five species of salmonid occur in the study area and all have been documented in harbor seal diet. Chinook Salmon (Oncorhynchus tshawytscha) was the only salmonid species confirmed by the scat samples of our study; however, Pink Salmon are the salmonid species most commonly consumed by harbor seals in the San Juan Islands (Lance et al., 2012). Pink Salmon runs in the northern Puget Sound were relatively abundant during the study period, but abundance indices indicate Chinook Salmon remained at critically depressed levels through $2008 .^{5}$ Salmonid

\footnotetext{
${ }^{5}$ Salmonid stock inventory ( $\mathrm{SaSi}$ ). Washington Department of Fish \& Wildlife. [Available from http://wdfw.wa.gov/ mapping/salmonscape/index.html.]
} 
abundance along the west coast of North America is linked to cooler than average ocean water temperatures. The high salmonid consumption values in our study may reflect higher than average salmonid abundance driven by changes (warm phase through 2005, neutral-to-cold phase after 2005) caused by the Pacific Decadal Oscillation since approximately 2006 (Mantua et al., 1997). We suggest that the overall high consumption rates of herring and salmonids (along with great uncertainty in these consumption rates) by harbor seals found in this study indicate that harbor seal consumption should be examined on broader spatial and historical scales to further explore the potential effect of harbor seal consumption on prey groups.

\section{Conclusions}

Harbor seals are a large-bodied and abundant predator whose consumption of depressed fish populations may conflict with regional fish recovery goals. This study established baseline consumption estimates for major prey groups and highlighted the potential range of consumption for the most common minor prey groups in the San Juan Islands region. Although there was great uncertainty in quantitative diet composition of harbor seals, salmonids and herring clearly constituted the majority of biomass consumed during the study period. Rockfish, one of the fish groups for which marine reserves are being planned, were among the minor prey groups consumed. The relative importance of prey items in harbor seal diet can be tested with future diet data in a model framework that incorporates estimates of uncertainty, similar to the one used in this study. Relation of consumption rates to mortality rates for any of the depressed fish species will require a multidisciplinary approach because of the complexity of harbor seal diet.

In this study, we explored how changes in the age structure of the harbor seal population influenced consumption values and found age structure to have relatively little influence. However, more work is needed to establish the current age structure of the harbor seal population because it may have significant implications for prediction of harbor seal body size, which strongly controlled model predictions. In further modeling exercises, the variables that most heavily influenced consumption values (body size of seals and quantitative diet composition) should be considered as some of the most important factors for prediction of consumption and food requirements of harbor seals in the study area.

\section{Acknowledgments}

We would like to thank N. Schwarck, G. McKeen, and members of the Marine Behavior and Ecology Laboratory of the Western Washington University for logistical support in field work. The lead author was supported through National Science Foundation Grant No. 0550443 awarded to A. Acevedo-Gutiérrez, a research assistantship from Padilla Bay National Estuarine Research Reserve, and the Office of Research and Sponsored Programs and the Biology Department at Western Washington University. Suggestions from 3 anonymous reviewers substantially improved previous versions of this manuscript.

\section{Literature cited}

Allison, G. W., J. Lubchenco, and M. H. Carr.

1998. Marine reserves are necessary but not sufficient for marine conservation. Ecol. Appl. 8:S79-S92.

Anthony, J. A., D. D. Roby, and K. R. Turco.

2000. Lipid content and energy density of forage fishes from the northern Gulf of Alaska. J. Exp. Mar. Biol. Ecol. 248:53-78.

Beck, C. A., W. D. Bowen, and S. Iverson.

2003. Sex differences in the seasonal patterns of energy storage and expenditure in a phocid seal. J. Anim. Ecol. 72:280-291.

Bigg, M. A.

1969. The harbour seal in British Columbia. Bull. J. Fish. Res. Board Can. 172:1-33.

Bjørge, A., T. Bekkby, V. Bakkestuen, and E. Framstad.

2002. Interactions between harbour seals, Phoca vitulina, and fisheries in complex coastal waters explored by combined geographic information system (GIS) and energetics modelling. ICES J. Mar. Sci. 59:29-42.

Bowen, W. D., D. J. Boness, and S. J. Iverson.

1999. Diving behaviour of lactating harbour seals and their pups during maternal foraging trips. Can. J. Zool. 77:978-988.

Bowen, W. D., O. T. Oftedal, and D. J. Boness.

1992. Mass and energy transfer during lactation in a small phocid, the harbor seal (Phoca vitulina). Physiol. Zool. 65:844-866.

Boyd, I. L.

2002. Estimating food consumption of marine predators: Antarctic fur seals and macaroni penguins. J. Appl. Ecol. 39:103-119.

Bundy, A.

2001. Fishing on ecosystems: the interplay of fishing and predation in Newfoundland-Labrador. Can. J. Fish. Aquat. Sci. 58:1153-1167.

Casper, R. M., S. N. Jarman, B. E. Deagle, N. J. Gales, and M. A. Hindell.

2007. Detecting prey from DNA in predator scats: a comparison with morphological analysis, using Arctocephalus seals fed a known diet. J. Exp. Mar. Biol. Ecol. 347:144-154.

Chassot, E., D. Duplisea, M. O. Hammill, A. Caskanette, N. Bousquet, Y. Lambert, and G. Stenson.

2009. Role of predation by harp seals Pagophilus groenlandicus in the collapse and non-recovery of northern Gulf of St. Lawrence cod Gadus morhua. Mar. Ecol. Prog. Ser. 379:279-297.

Coltman, D. W., W. D. Bowen, S. J. Iverson, and D. J. Boness. 1998. The energetics of male reproduction in an aquatically mating pinniped, the harbour seal. Physiol. Zool. 71:387-399. 
Deagle, B. E., and D. J. Tollit.

2007. Quantitative analysis of prey DNA in pinniped faeces: potential to estimate diet composition? Conserv. Genet. 8:743-747.

DeMaster, D. P., C. W. Fowler, S. L. Perry, and M. F. Richlen. 2001. Predation and competition: the impact of fisheries on marine-mammal populations over the next one hundred years. J. Mammal. 82:641-651.

Fanshawe, S., G. R. Vanblaricom, and A. A. Shelly.

2003. Restored top carnivores as detriments to the performance of marine protected areas intended for fishery sustainability: a case study with red abalones and sea otters. Conserv. Biol. 17:273-283.

Federal Register.

2010. Endangered and threatened wildlife and plants: threatened status for the Puget Sound/Georgia Basin distinct population segments of yelloweye and canary rockfish and endangered status for the Puget Sound/ Georgia Basin distinct population segment of bocaccio rockfish. Final Rule. Federal Register: vol. 75, no. 81, April 28, p. 22276-22290. GPO, Washington, DC.

Fluharty, D.

2000. Habitat protection, ecological issues, and implementation of the Sustainable Fisheries Act. Ecol. Appl. 10:325-337.

Fowler, C. W.

1981. Comparative population dynamics in large mammals. In Dynamics of large mammal populations (C. W. Fowler and T. D. Smith, eds.), p. 437-455. John Wiley $\&$ Sons, New York.

$\mathrm{Fu}, \mathrm{C}$., R. Mohn, and P. L. Fanning.

2001. Why the Atlantic cod (Gadus morhua) stock off eastern Nova Scotia has not recovered. Can. J. Fish. Aquat. Sci. 58:1613-1623.

Hardee, S.

2008. Movements and home ranges of harbor seals $(P h$ oca vitulina) in the inland waters of the Pacific Northwest. M.S. thesis, 148 p. Western Washington Univ., Belligham, WA.

Härkönen, T., and M.-P. Heide-Jørgensen.

1991. The harbour seal Phoca vitulina as a predator in the Skagerrak. Ophelia 34:191-207.

Harvey, J. T.

1989. Assessment of errors associated with harbour seal (Phoca vitulina) faecal sampling. J. Zool. 219:101-111.

Harvey, J. T., T. R. Loughlin, M. A. Perez, and D. S. Oxman. 2000. Relationship between fish size and otolith length for 63 species of fishes from the eastern North Pacific Ocean. NOAA Tech. Rep. NMFS 150, 38 p.

Hauser, D. D. W., C. S. Allen, H. B. J. Rich, and T. P. Quinn. 2008. Resident harbor seals (Phoca vitulina) in Iliamna Lake, Alaska: summer diet and partial consumption of adult sockeye salmon (Oncorhynchus nerka). Aquat. Mamm. 34:303-309.

Hiby, A. R., and J. Harwood.

1985. The effects of variation in population parameters on the energy requirements of a hypothetical grey seal population. In Marine mammals and fisheries (J. R. Beddington, R. J. H. Beverton, and D. M. Lavigne, eds.), p. 337-343. G. Allen \& Unwin, London.

Hoelzel, A. R.

2002. Marine mammal biology: an evolutionary approach, 432 p. Blackwell Publ. Co., Oxford.
Howard, S. M. S.

2009. Energetic requirements and prey consumption of harbor seals (Phoca vitulina) in the San Juan Islands, WA. M.S. thesis, 106 p. Western Washington Univ., Bellingham, WA.

Huber, H. R., S. J. Jeffries, R. F. Brown, R. L. DeLong, and G. Van Blaricom.

2001. Correcting aerial survey counts of harbor seals (Phoca vitulina richardsi) in Washington and Oregon. Mar. Mamm. Sci. 17:276-293.

Innes, S., D. M. Lavigne, W. M. Earle, and K. M. Kovacs. 1987. Feeding rates of seals and whales. J. Anim. Ecol. 56:115-130.

Jeffries, S. J., H. R. Huber, J. Calambokidis, and J. Laake. 2003. Trends and status of harbor seals in Washington State: 1978-1999. J. Wildl. Manage. 67:208-219.

Kleiber, M.

1975. The fire of life: an introduction to animal energetics, 453 p. R. E. Krieger Publ., Huntington, NY.

Laake, J., P. Browne, R. L. DeLong, and H. R. Huber. 2002. Pinniped diet composition: a comparison of estimation models. Fish. Bull. 100:434-447.

Lance, M. M., W. Chang, S. J. Jeffries, S. F. Pearson, and A. Acevedo-Gutiérrez.

2012. Harbor seal diet in northern Puget Sound: implications for the recovery of depressed fish stocks. Mar. Ecol. Prog. Ser. 464:257-271.

Lavigne, D. M., W. Barchard, S. Innes, and N. A. Øritsland. 1982. Pinniped bioenergetics. In Mammals in the seas: small cetaceans, seals, sirenians, and otters, p. 191-235. FAO, Rome.

Lavigne, D. M., S. Innes, G. A. J. Worthy, K. M. Kovacs, O. J. Schmitz, and J. P. Hickie.

1986. Metabolic rates of seals and whales. Can. J. Zool. 64:279-284.

Love, M. S., M. Yoklavich, and L. Thorsteinson. 2002. The rockfishes of the northeast Pacific, 432 p. Univ. California Press, Berkeley, CA.

Mantua, N., S. R. Hare, Y. Zhang, J. M. Wallace, and R. C. Francis.

1997. A Pacific interdecadal climate oscillation with impacts on salmon production. Bull. Am. Meteorol. Soc. 78:1069-1079.

Markussen, N. H., M. Ryg, and N. A. Øritsland.

1990. Energy requirements for maintenance and growth of captive harbour seals, Phoca vitulina. Can. J. Zool. 68:423-426.

1994. The effect of feeding on the metabolic rate in harbour seals (Phoca vitulina). J. Comp. Physiol., B 164:89-93.

Mecenero, S., S. P. Kirkman, and J. P. Roux.

2006. A refined fish consumption model for lactating Cape fur seals (Arctocephalus pusillus pusillus), based on scat analyses. ICES J. Mar. Sci. 63:1551-1566.

Mills, C. E., and K. Rawson.

2004. Outlook grim for North Pacific rockfish. Rockfish symposium, Friday Harbor Laboratories, Univ. Washington, WA. Fish Fish. 5:178-180.

Mohn, R., and W. D. Bowen.

1996. Grey seal predation on the eastern Scotian Shelf: modelling the impact on Atlantic cod. Can. J. Fish. Aquat. Sci. 53:2722-2738.

Murray, S. N., R. F. Ambrose, J. A. Bohnsack, L. W. Botsford, M. H. Carr, G. E. Davis, P. K. Dayton, D. Gotshall, D. R. Gunderson, M. A. Hixon, J. Lubchenco, M. Mangel, A. Mac- 
Call, D. A. McArdle, J. C. Ogden, J. Roughgarden, R. M. Starr, M. J. Tegner, and M. M. Yoklavich.

1999. No-take reserve networks: sustaining fishery populations and marine ecosystems. Fisheries 24:11-25.

Musick, J. A., M. M. Harbin, S. A. Berkeley, G. H. Burgess, A. M. Eklund, L. Findley, R. G. Gilmore, J. T. Golden, D. S. Ha, G. R. Huntsman, J. C. McGovern, S. J. Parker, S. G. Poss, E. Sala, T. W. Schmidt, G. R. Sedberry, H. Weeks, and S. G. Wright.

2000. Marine, estuarine, and diadromous fish stocks at risk of extinction in North America (exclusive of Pacific salmonids). Fisheries 25:6-30.

NMFS (National Marine Fisheries Service).

1997. Investigation of scientific information on the impacts of California sea lions and Pacific harbor seals on salmonids and on the coastal ecosystems of Washington, Oregon, and California. NOAA Tech. Memo. NMFSNWFSC-28, $172 \mathrm{p}$.

Olesiuk, P. F.

1993. Annual prey consumption by harbour seals (Phoca vitulina) in the Strait of Georgia, British Columbia. Fish. Bull. 91:491-515.

Orr, A. J., J. L. Laake, M. I. Dhruw, A. S. Banks, R. L. DeLong, and H. R. Huber.

2003. Comparison of processing pinniped scat samples using a washing machine and nested sieves. Wildl. Soc. Bull. 31:253-257.

Overholtz, W. J., and J. S. Link.

2007. Consumption impacts by marine mammals, fish, and seabirds on the Gulf of Maine-Georges Bank Atlantic herring (Clupea harengus) complex during the years 1977-2002. ICES J. Mar. Sci. 64:83-96.

Patterson, J., and A. Acevedo-Gutiérrez.

2008. Tidal influence on the haul-out behavior of harbor seals (Phoca vitulina) at a site available at all tide levels. Northwest. Nat. 89:17-23.

Paul, A. J., J. M. Paul, and E. D. Brown.

1998. Fall and spring somatic energy content for Alaskan Pacific herring (Clupea pallasi Valenciennes 1847) relative to age, size and sex. J. Exp. Mar. Biol. Ecol. 223:133-142.

Payne, S. A., B. A. Johnson, and R. S. Otto.

1999. Proximate composition of some north-eastern $\mathrm{Pa}$ cific forage fish species. Fish. Oceanogr. 8:159-177.

Perez, M. A.

1994. Calorimetry measurements of energy value of some Alaskan fishes and squids. NOAA Tech Memo. NMFS-AFSC-32, $32 \mathrm{p}$.

Phillips, E. M., and J. T. Harvey.

2009. A captive feeding study with the Pacific harbor seal (Phoca vitulina richardii): implications for scat analysis. Mar. Mamm. Sci. 25:373-391.

$\mathrm{R}$ Development Core Team.

2008. R: A language and environment for statistical computing. R Foundation for Statistical Computing. [Available from: http://www.R-project.org, accessed June 2009.]

Roby, D. D., D. E. Lyons, D. P. Craig, K. Collis, and G. H. Visser. 2003. Quantifying the effect of predators on endangered species using a bioenergetics approach: Caspian terns and juvenile salmonids in the Columbia River estuary. Can. J. Zool. 81:250-265.
Roni, P., T. J. Beechie, R. E. Bilby, F. E. Leonetti, M. M. Pollock, and G. R. Pess.

2002. A review of stream restoration techniques and a hierarchical strategy for prioritizing restoration in $\mathrm{Pa}-$ cific Northwest watersheds. N. Am. J. Fish. Manage. 22:1-20.

Rosen, D. A. S., and D. Renouf.

1998. Correlates of seasonal changes in metabolism in Atlantic harbour seals (Phoca vitulina concolor). Can. J. Zool./Rev. Can. Zool. 76:1520-1528.

Sala, E., and M. Zabala.

1996. Fish predation and the structure of the sea urchin Paracentrotus lividus populations in the NW Mediterranean. Mar. Ecol. Prog. Ser. 140:71-81.

Schindler, D. E., M. D. Scheuerell, J. W. Moore, S. M. Gende, T. B. Francis, and W. J. Palen.

2003. Pacific salmon and the ecology of coastal ecosystems. Front. Ecol. Environ. 1:31-37.

Schusterman, R. J., and R. L. Gentry.

1971. Development of a fatted male phenomenon in California sea lions. Dev. Psychobiol. 4:333-338.

Shears, N. T., and R. C. Babcock.

2002. Marine reserves demonstrate top-down control of community structure on temperate reefs. Oecologia 132:131-142.

Shears, N. T., R. V. Grace, N. R. Usmar, V. Kerr, and R. C. Babcock.

2006. Long-term trends in lobster populations in a partially protected vs. no-take Marine Park. Biol. Conserv. 132:222-231.

Shelton, P. A., W. G. Warren, G. B. Stenson, and J. W. Lawson. 1997. Quantifying some of the major sources of uncertainty associated with estimates of harp seal prey consumption. Part II: Uncertainty in consumption estimates associated with population size, residency, energy requirement and diet. J. Northwest Atl. Fish. Sci. 22:303-315.

Simenstad, C. A., B. S. Miller, C. F. Nyblade, K. Thornburgh, and L. J. Bledsoe.

1979. Food web relationships of northern Puget Sound and the Strait of Juan de Fuca: a synthesis of the available knowledge. Interagency Energy/Environment R\&D Program Report, 342 p. U.S. Environmental Protection Agency, Washington, D.C.

Sparling, C. E., and M. A. Fedak.

2004. Metabolic rates of captive grey seals during voluntary diving. J. Exp. Biol. 207:1615-1624.

Stenson, G. B., M. O. Hammill, and J. W. Lawson.

1997. Predation by harp seals in Atlantic Canada: preliminary consumption estimates for Arctic cod, capelin and Atlantic cod. J. Northwest Atl. Fish. Sci. 22:137-154.

Stout, H. A., R. G. Gustafson, W. H. Lenarz, B. B. McCain, D. M. VanDoornik, T. L. Builder, and R. D. Methot.

2001. Status review of Pacific herring in Puget Sound, Washington. NOAA Tech. Memo. NMFS-NWFSC-45, $175 \mathrm{p}$.

Tollit, D., S. Heaslip, B. Deagle, S. J. Iverson, R. Joy, D. Rosen, and A. Trites.

2006. Estimating diet composition in sea lions: which technique to choose? In Sea lions of the world: Proceedings of the symposium sea lions of the world. Conservation and Research in the 21st Century, September 30-October 3, 2004, Anchorage, Alaska (A. Trites, ed.), 
p. 293-307. Alaska Sea Grant College Program, Univ. Alaska, Fairbanks, AK.

Tollit, D. J., S. G. Heaslip, T. K. Zeppelin, R. Joy, K. A. Call, and A. W. Trites.

2007. A method to improve size estimates of walleye pollock (Theragra chalcogramma) and Atka mackerel (Pleurogrammus monopterygius) consumed by pinnipeds: digestion correction factors applied to bones and otoliths recovered in scats. Fish. Bull. 102:498-508.

Trumble, S. J., P. S. Barboza, and M. A. Castellini.

2003. Digestive constraints on an aquatic carnivore: effects of feeding frequency and prey composition on harbor seals. J. Comp. Physiol., B 173:501-509.

Trzcinski, M. K., R. Mohn, and B. W. Bowen.

2006. Continued decline of an Atlantic cod population: how important is grey seal predation? Ecol. Appl. 16:2276-2292.

\section{Appendix}

Modified age structures (minimum-maximum number of seals) used in alternative model scenarios with increased numbers of adults in the harbor seal popula-
Van Pelt, T. I., J. F. Piatt, B. K. Lance, and D. D. Roby. 1997. Proximate composition and energy density of some north Pacific forage fishes. Comp. Biochem. Physiol., A: Mol. Integr. Physiol. 118A:1393-1398.

Venables, W. N., and B. D. Ripley.

2002. Modern applied statistics with S, 512 p. Springer, New York.

Winship, A. J., A. W. Trites, and D. A. S. Rosen.

2002. A bioenergetic model for estimating the food requirements of Steller sea lions Eumetopias jubatus in Alaska, USA. Mar. Ecol. Prog. Ser. 229:291-312.

Wright, B. E., S. D. Riemer, R. F. Brown, A. M. Ougzin, and K. A. Bucklin.

2007. Assessment of harbor seal predation on adult salmonids in a Pacific Northwest estuary. Ecol. Appl. $17: 338-351$.

tion. Pup numbers did not change from the basic age structure. $+25 \%, 50 \%$, and $100 \%$ correspond to percent increases in numbers of adults in the population.

\begin{tabular}{lccc} 
Seal age class & Basic $+25 \%$ & Basic $+50 \%$ structure & Basic $+100 \%$ structure \\
\hline Adult female & $1485-1673$ & $1782-2007$ & $2376-2676$ \\
Adult male & $339-393$ & $407-471$ & $542-628$ \\
Subadult female & $1997-2572$ & $1688-2251$ & $1068-1610$ \\
Subadult male & $2388-3273$ & $2316-3200$ & $2170-3054$
\end{tabular}

